\title{
Fracture toughness at cryogenic temperatures of ultrafine-grained Ti-6Al-4V alloy processed by ECAP
}

${ }^{a}$ Irina P. Semenova, ${ }^{a}$ Julia M. Modina, ${ }^{\text {a,b }}$ Alexander V. Polyakov*, ${ }^{c}$ Gennady V. Klevtsov, ${ }^{c}$ Nataly A. Klevtsova, ${ }^{c}$ Irina N. Pigaleva, , ${ }^{\mathrm{a}, \mathrm{b}}$ Ruslan Z. Valiev and ${ }^{\mathrm{d}}$ Terence G. Langdon ${ }^{a}$ Ufa State Aviation Technical University, 12 K. Marx street, 450008 Ufa, Russia ${ }^{b}$ Saint Petersburg State University, 7/9 Universitetskaya nab., St. Petersburg, 199034, Russia ${ }^{c}$ Togliatti State University, Samara region, 14 Belorusskaya str., Tolyatti 445667, Russia

${ }^{d}$ Materials Research Group, Faculty of Engineering and the Environment, University of Southampton, Southampton SO17 1BJ, UK

*alex-v.polyakov@mail.ru

\begin{abstract}
This research is focused on a study of the relationship between mechanical behavior, microstructure and fracture toughness of a Ti-6Al-4V alloy in both coarse-grained (CG) and ultrafine-grained (UFG) conditions. The UFG state with a primary alpha-phase grain size, but with different orientations with respect to the testing direction, was produced by equal-channel angular pressing (ECAP) after thermo-mechanical treatment. Fracture toughness and mechanical testing were conducted at a temperature of $-196^{\circ} \mathrm{C}$. A duplex UFG structure formation in the Ti$6 \mathrm{Al}-4 \mathrm{~V}$ alloy led to an enhancement of yield stress and a decrease in the fracture toughness at $-196{ }^{\circ} \mathrm{C}$ by comparison with the $\mathrm{CG}$ alloy. The lowest values of fracture toughness were observed in a sample in which there were elongated grains lying parallel to the loading direction during testing compared to the situation where the grains were perpendicular to this direction. The reasons for the reduction in fracture toughness in the UFG Ti alloy are discussed.
\end{abstract}

Key words: Cryogenic temperatures; Duplex ultrafine-grained structure; Fracture toughness; Titanium alloy; Uniform elongation. 


\section{Introduction}

Two-phase $\mathrm{Ti}$ alloys are widely used as structural materials in aircraft and engine construction due to their high specific strength and corrosion resistance. One of the most utilized alloys in industry is Ti-6Al-4V owing to an effective combination of alloying elements and good technological properties [1]. It is well known that the strength, ductility, fatigue endurance limit, creep strength and fracture toughness determine the efficiency of structural materials. The brittle fracture strength or crack resistance (fracture toughness), which is determined during static single loading and characterized by a $K_{\mathrm{IC}}$ value, is an especially important characteristic of materials which becomes a critical factor in the design of parts for technological applications [2]. In particular, the fracture toughness of Ti-6Al-4V $\left(\sim 60 \mathrm{MPa} \cdot \mathrm{m}^{-2}\right.$ on average $)$ is higher than for $\mathrm{Al}$ alloys $\left(\sim 35 \mathrm{MPa} \cdot \mathrm{m}^{-2}\right)$ but lower than in steels $\left(\sim 115 \mathrm{MPa} \cdot \mathrm{m}^{-2}\right)[2]$. This parameter of the Ti$6 \mathrm{Al}-4 \mathrm{~V}$ alloy depends strongly on the oxygen content and the thermomechanical treatment (TMT) regime when the $K_{\mathrm{IC}}$ value can change in the range from $\sim 30$ to $\sim 100 \mathrm{MPa} \cdot \mathrm{m}^{-2}$ [2]. This is because the crack propagation resistance is a structure-sensitive parameter and, depending primarily on the TMT regime used for the Ti-6Al-4V alloy, the structure parameters such as the size of the $\beta$-phase grains and the shape and size of the $\alpha$-phase may change significantly $[1,2]$.

The formation of ultrafine-grained (UFG) states in metals and alloys by different severe plastic deformation (SPD) techniques, including the development of true nanostructured materials with average grain sizes of $<100 \mathrm{~nm}$, is one of the most promising approaches for improving the strength and ductility characteristics and significantly increasing the fatigue endurance limit and other performance properties [3-7]. For example, it is established that UFG structure formation in titanium and the Ti-6Al-4V alloy may lead to a high level of strength, improved fatigue endurance limit and even to a superplastic forming capability [8-13] and this creates conditions for use of this alloy under extreme conditions. Accordingly, a study of crack resistance in this alloy in the UFG state is required urgently in order to achieve greater efficiency 
in the design of real structures. It is important to note also that processing by SPD techniques may induce phase transformations in the Ti-6Al-4V alloy [14].

Recent studies have shown that the formation of a nanostructured state in metals leads to a decrease in the fracture toughness as shown, for example, in nickel, iron and titanium [15-17] and this effect is frequently associated with the decrease in the strain hardening capacity of nanostructured materials $[17,18]$. It is well known that the relationship between $K_{\text {IC }}$ and the strain-hardening coefficient is described by the relationship [19]:

$$
K_{\mathrm{IC}}=n \sqrt{c E \sigma_{\mathrm{ys}} \varepsilon_{\mathrm{f}}}
$$

where $n$ is the strain hardening coefficient, $c$ is a constant, $\sigma_{\mathrm{ys}}$ is the yield strength, $E$ is the elastic modulus and $\varepsilon_{\mathrm{f}}$ is the fracture strain.

These UFG materials often demonstrate an early localization and neck formation because of complex interactions between dislocation nucleation and accumulation within the UFG structure [20]. However, to date there are only a limited number of reports describing investigations of the fracture toughness of nanostructured materials and this is associated with experimental problems such as the small sample size after SPD processing. As is well known [21], the main fracture mechanics criterion in the evaluation of $K_{\mathrm{IC}}$ is a fulfillment of the relationship $t /\left(K_{\mathrm{IC}} / Y S_{2}\right)^{2} \geq 2.5$, where $t$ is the sample thickness, and this must ensure fracture under conditions of plane strain. In addition, at higher temperatures a ductile cleavage zone may develop so the values of $K_{\text {IC }}$ may be overestimated.

In the present experiments, an UFG structure formation was achieved in a Ti-6Al-4V alloy by equal-channel angular pressing (ECAP) and this led to the production of bulk billets which permitted the machining of standard samples for evaluating the fracture toughness in the UFG alloy. In order to create the ultimate state of the material under conditions of maximum constraint of plastic deformation, tests were conducted in liquid nitrogen at a temperature of $-196^{\circ} \mathrm{C}$. Specimens were produced by ECAP with the same primary alpha-phase grain size but 
with different grain orientations relative to the testing direction. Thus, the aim of this investigation was to study the relationship between the mechanical behavior, microstructure and fracture toughness of the Ti-6Al-4V alloy in duplex coarse grained (CG) and UFG conditions.

\section{2, Experimental materials and procedures}

The experiments were conducted with a Ti-6Al-4V alloy produced in the form of hotrolled rods with diameters of $40 \mathrm{~mm}$ and containing the following chemical composition (in wt $\%$ ): $6.2 \% \mathrm{Al}, 4.3 \% \mathrm{~V}, 0.02 \% \mathrm{Zr}, 0.039 \% \mathrm{Si}, 0.16 \% \mathrm{Fe}, 0.06 \% \mathrm{C}, 0.168 \% \mathrm{O}, 0.015 \% \mathrm{~N}$, $0.003 \% \mathrm{H}$, Ti-base. The results of differential scanning calorimetry (DSC) showed the temperature of the polymorphous transformation $\left(T_{\mathrm{PT}}\right)$ as $975 \pm 5{ }^{\circ} \mathrm{C}$. In order to produce the duplex structure in a Ti-6Al-4V rod, the billets were subjected to a standard heat treatment (HT) of quenching at $960{ }^{\circ} \mathrm{C}\left(\sim 20^{\circ} \mathrm{C}\right.$ lower than $\left.T_{P T}\right)$ for $1 \mathrm{~h}$ and then tempering at $675{ }^{\circ} \mathrm{C}$ for $4 \mathrm{~h}$. This state is hereafter referred to as "HT". In order to form a structure designated "UFG1" in billets having diameters of $40 \mathrm{~mm}$, ECAP was used at a temperature of $650{ }^{\circ} \mathrm{C}$ for 6 passes with a die-set having a channel angle of $120^{\circ}$ and using route $\mathrm{B}_{\mathrm{C}}$ where the sample is rotated by $90^{\circ}$ between each pass. Samples were cut in the longitudinal sections of the billets as shown in Fig. 1a. In addition, the billets processed by ECAP were subjected to forging at $700^{\circ} \mathrm{C}$ close to the ECAP temperature such that the strain accumulated after upsetting was around $\varepsilon \approx 30 \%$ and the strain rate was not higher than $10^{-1} \mathrm{~s}^{-1}$ : this state was designated "UFG2". Samples were then cut from the forged plates following the procedure outlined in Fig. $1 \mathrm{~b}$.

Cylindrical specimens with diameters of $3 \mathrm{~mm}$ and gauge lengths of $15 \mathrm{~mm}$ were used for the tensile tests. The tensile testing was performed at an initial strain rate of $1.0 \times 10^{-3} \mathrm{~s}^{-1}$ in liquid nitrogen using an Instron testing machine operating at a constant rate of cross-head displacement. A relatively uniform elongation of the samples was obtained from the engineering stress-strain curves as a value corresponding to the maximum forcing.

The alloys were tested for static crack resistance $K_{\mathrm{IC}}$ on prismatic samples with thicknesses of $10 \mathrm{~mm}$ using three-point bending in liquid nitrogen with the aim of ensuring 
conditions of plane straining of the samples. In this procedure, a fatigue crack was grown in the samples and testing for static crack resistance was performed on an Instron testing machine [21]. The tests were performed in accordance with [21], 5 samples of each state (HT, UFG1 and UFG2) were tested.

The microstructures of samples were analyzed by transmission electron microscopy (TEM) with the foils prepared using electrical discharge machining, mechanical thinning to a thickness of $\sim 100 \mu \mathrm{m}$ and then electro-polishing using a TenuPol-5 facility with a solution of 5\% perchloric acid, $35 \%$ butanol and $60 \%$ methanol at a polishing temperature within the range from -20 to $-35{ }^{\circ} \mathrm{C}$. The microstructures were examined using a JEOL JEM 2100 microscope operating with an accelerating voltage of $200 \mathrm{kV}$. The surface fracture features after testing were examined using a SIGMA set from Zeiss and a JEOL JSM 6390 scanning electron microscope (SEM).

\section{Experimental results}

\subsection{Microstructure of Ti-6Al-4V sample in the conditions HT, UFG1 and UFG2}

Figure 2 displays the microstructure of the alloy after HT, which is a mixed globularplatelet structure consisting of grains of primary $\alpha_{p}$-phase with an average size of $\sim 8 \mu \mathrm{m}$, a volume fraction of $\sim 30 \%$ (Fig. 2a) and areas $(\alpha+\beta)$ with thin plate-like structures (Fig. 2b). An X-ray phase analysis showed the ratios of the $\alpha$ - and $\beta$-phases were about 85 and $15 \%$, respectively.

Figures 3 and 4 display the UFG1 and UFG2 structures. The overall structure is shown in Fig. $3 \mathrm{a}$ and the interiors of the poorly-deformed primary $\alpha_{p}$-phase grains in Fig. $3 \mathrm{c}$ consist of rather poorly-oriented dislocation substructures. The elongated primary $\alpha_{p}$-phase grains in the UFG1 structure are perpendicular to the testing direction (Fig. 3a) and in UFG2 they are parallel to the loading direction (Fig. 4a). The average size of the ultrafine grains/subgrains in the $(\alpha+$ $\beta$ ) regions is $\sim 350 \mathrm{~nm}$ and their shapes are essentially equiaxed in both the longitudinal and transverse directions of the billet (Figs $3 b$ and $4 b$ ). 


\subsection{Mechanical properties of Ti $-6 \mathrm{Al}-4 \mathrm{~V}$ at room temperature and $-196{ }^{\circ} \mathrm{C}$}

Figure 5 shows typical tensile curves of the Ti-6Al-4V alloy samples in the HT and UFG states at room and cryogenic temperature. The shape of the curves characterizes a similar mechanical behavior of the alloy in CG and UFG states at both temperatures. It should be noted that an increase in the ultimate tensile strength due to grain refinement and UFG structure formation has only a minor effect on the total elongation of the sample, but visibly reduces the values of uniform elongation $\delta_{\mathrm{u}}$, as testified by a change in the shape of the curves of the samples with the structures UFG1 and UFG2. Such a behavior often characterizes SPD-processed metals and alloys [18].

Table 1 lists the mechanical properties of the alloy in the various studied states both at room temperature and at the cryogenic temperature. The samples with the duplex structure produced by thermal treatment demonstrate typical mechanical properties for this structure type at room temperature with an ultimate tensile strength of $\sim 950 \mathrm{MPa}$ and a relative elongation of $\sim 12 \%$ [2]. ECAP processing enhances the ultimate tensile strength to $\sim 1180 \mathrm{MPa}$ and reduces the total and uniform elongations to $\sim 9.0$ and $\sim 1.1 \%$, respectively, due to a refinement of the $\alpha$ phase grains and the formation of a duplex UFG structure which takes no less than $\sim 70 \%$ of the billet volume (Fig. 3a). The samples with the UFG2 microstructure show similar properties as recorded in Table 1. A yield stress enhancement and a uniform elongation reduction to $\sim 0.7 \%$ were recorded.

Much attention was devoted to the mechanical properties at the cryogenic temperature since the tests for the evaluation of $K_{\mathrm{IC}}$ were conducted at $-196{ }^{\circ} \mathrm{C}$. In general, the changes in the mechanical characteristics at the cryogenic temperature were similar to the changes in mechanical properties at room temperature as recorded in Table 1. The significant increase in the UTS and YS at cryogenic temperature in both alloy states appears to be due to the suppression of thermally-activated processes of dislocation motion which require higher stresses for dislocation glide [22]. 


\subsection{Fracture toughness $K_{\mathrm{IC}}$ of $T i-6 A l-4 V$ at $T=-196{ }^{\circ} \mathrm{C}$}

Table 2 presents the averaged values with a standard deviation for 5 samples of the static crack resistance $K_{\mathrm{IC}}$ at $-196{ }^{\circ} \mathrm{C}$ in Ti-6Al-4V in different states. An estimate of the ratio $t /\left(K_{\mathrm{IC}} / Y S_{2}\right)^{2}$ for all the studied states is given in Table 2 and all samples are in plane-strain state during testing. The values obtained are larger than 2.5 , i.e. the sizes of the tested samples satisfy this condition at a test temperature of $-196^{\circ} \mathrm{C}$.

The results of these studies show that the $K_{\mathrm{IC}}$ value is reduced in the alloy with a yield stress increase due to the UFG structure formation. Figure 6 shows the dependence of $K_{\mathrm{IC}}$ on the uniform elongation, $\delta_{\mathrm{u}}$, for the HT, UFG1 and UFG 2 structural states of the alloy. It should be noted that the lowest fracture toughness was observed in the UFG2 samples in which the loading direction was along the elongated $\alpha_{p}$-grains. This contrasts with UFG1 where the testing direction was perpendicular to the elongated $\alpha_{p}$-grains (Fig. 3 and 4).

\subsection{Fracture surfaces of samples after testing.}

Figure 7 shows the fracture surfaces in the Ti-6Al-4V samples in the different structural states and the arrows in Fig. 7 depict the start of brittle separation in all samples from the grown fatigue crack (the pre-crack).

In these samples, inspection shows there are no regions of stable subcritical development of the crack in a plastic zone, which indicates the creation of a plane-strain state of the samples during testing. In all structural states there is a classical micro-ductile fracture with typical voids having sizes close to the grain diameter. This means that the main failure mechanism in the $\mathrm{CG}$ and UFG samples, irrespective of the loading direction, is the formation of voids and their growth and coalescence prior to pre-crack tip propagation. It is apparent from Table 2 that the samples with UFG2 structure have lower values of fracture toughness compared to the UFG1 samples $\left(\sim 34\right.$ and $\sim 28 \mathrm{MPa} \cdot \mathrm{m}^{-2}$, respectively).

Figures $8 \mathrm{a}$ and $8 \mathrm{~b}$ show that in the two-phase areas of the structure the size of pits is practically comparable to the size of grains and subgrains and the character of the failure is 
mainly intercrystalline which is generally typical of UFG metals [17,23]. It should be noted that for UFG1 in the coarse grains of the $\alpha_{p}$-phase the crack propagation is mainly of a transcrystalline character as testified by the flat facets which correspond to definite crystallographic planes which are comparable to the grain sizes of the $\alpha_{p}$-phase (Fig. 8a). The relief of the UFG2 sample is more homogeneous along the direction of crack propagation compared to UFG1 (Fig. 8b). For the UFG1 structure, when the grains of the primary $\alpha$-phase are located perpendicular to the direction of crack growth it appears that they constrain crack propagation and branching [17].

\section{Discussion}

The results obtained within this research show that the formation of a UFG structure in Ti-6Al-4V leads to an increase in the yield stress in accordance with the Hall-Petch relationship both at room temperature and at the cryogenic temperature (Table 1). During the formation of the UFG structure the alloy ductility is reduced, where this generally characterizes materials processed by SPD $[17,18,24]$. It is also apparent that the total elongations of samples with UFG1 and UFG2 structures is about 2 times lower than in the samples after a standard heat treatment (Table 1). A more significant difference is observed in the value of the uniform elongation. It is known that in ultrafine grains the generation and accumulation of dislocations is hindered and therefore in UFG materials an early localization of strain and necking is generally observed during tensile testing [18]. It should be noted also that the total and uniform elongation values in the CG and UFG samples tested at room and cryogenic temperature are almost the same as documented in Table 1.

Testing of the UFG samples for fracture toughness, $K_{\mathrm{IC}}$, demonstrates the anticipated reduction in this parameter with the yield stress increase (Table 2) and the associated reduction of the uniform elongation value, $\delta_{u}$, which characterizes the capability of the material to strain hardening (Fig. 5). In earlier reports [25-27], the capability of the material to strain hardening was also connected with the difference between the UTS and YS which permits controlling and 
predicting the material fracture toughness. Such dependences have been obtained for different materials (Mg-6Zn-Mn alloy, Al-Li alloys, light-nitrogen steel, etc) [25-27]. For the Ti alloy TC21 with an equiaxed microstructure, a similar correlation was obtained when an increase of the difference between the UTS and the YS led to an enhancement of the fracture toughness $K_{\mathrm{IC}}$ [27].

A summary of the results obtained in this investigation is given in Fig. 9 which displays the dependences of fracture toughness on the difference between the UTS and YS at room temperature for the Ti-6Al-4V alloy in the annealed state, after quenching and aging, and for the results obtained in this study at $-196{ }^{\circ} \mathrm{C}(77 \mathrm{~K})$.

It is apparent from Fig. 9 that the fracture toughness of the CG alloy also depends on the material capability to strain hardening as demonstrated by the curves for the annealed and heattreated states. The $K_{\mathrm{IC}}$ of the CG samples at the same difference (UTS - YS) is much lower at $-196{ }^{\circ} \mathrm{C}$ compared to $K_{\mathrm{IC}}$ at room temperature where the values are $\sim 48$ and $\sim 70 \mathrm{MPa} \cdot \mathrm{m}^{-2}$, respectively. This is conditioned first of all by the creation of conditions of maximum suppression of plastic flow of the material at the cryogenic temperature. The dependence of $K_{\mathrm{IC}}$ on the difference of $U T S$ and $Y S$ at $-196{ }^{\circ} \mathrm{C}$ can be described by a linear regression equation of the form $\mathrm{Y}=11.1905 \mathrm{x}+19.8810$ with a correlation rate of $R^{2}=0.99$. A similar dependence was also reported for the TC21 alloy [27] as documented by the data recorded in Table 3. From Table 3 it is apparent also that the dependence of $K_{\mathrm{IC}}$ on $\delta_{\mathrm{u}}$ has a rectilinear character.

As already noted $[17,23]$, the main difference in the failure nature of the CG and UFG metals is the prevailing crack propagation along the grain boundaries in the UFG material due to the relatively long lengths associated with the boundaries. By contrast, in UFG materials there are potentially more locations for the formation of voids and nanocracks, as at grain boundaries and triple junctions, so that the individual shapes of the ultrafine grains will have a prevailing role in the crack propagation. This is demonstrated for single-phase pure metals in nanocrystalline and ultrafine-grained states where the fracture toughness is very sensitive to the 
shapes of the individual grains [28-30]. It is known that many SPD processes lead to elongations of grains along the billet axis and this contributes to a general anisotropy of the structure and properties.

In this research the objective was to evaluate two-phase alloys which, after processing by ECAP, have heterogeneous structures consisting of structural constituents with different morphologies. First, these are areas with two-phase UFG structures in which the grains and subgrains of the $\alpha$ and $\beta$-phases have relatively equiaxed shape in all crystallographic directions and with fractions of no less than $\sim 70 \%$ in both the UFG1 and UFG2 states (Fig. 3 and 4). Second, there are poorly-deformed elongated grains of the primary $\alpha$-phase which are perpendicular and parallel to the direction of testing in the UFG1 and UFG2 states, respectively. The results show that the UFG2 samples have lower values of fracture toughness compared to the UFG1 sample ( $\sim 34$ and $\sim 28 \mathrm{MPa} \cdot \mathrm{m}^{-2}$, respectively). It is reasonable to assume that these results are a consequence of the different orientations of the grains of the primary $\alpha$-phase with respect to the loading.

In UFG states of the alloy, there is an example of a bimodal structure where $\alpha_{\mathrm{p}}$ phase plays the role of large grains and two-phase regions play the role of the ultrafine-grained component of structure. In both cases, the mechanism of crack propagation during testing has a micro-ductile character. It is important to note also that the character of the crack propagation in the UFG1 and UFG2 samples is relatively similar with comparable values for the fracture toughness. In particular, in UFG regions, crack propagation takes place predominantly at grain/subgrain boundaries. It is shown in figures $8 \mathrm{a}$ and $8 \mathrm{~b}$, where size of dimples in the fracture surface of UFG samples after testing is similar to the grain size in the microstructure. However, the interphase boundaries of large grains of the $\alpha_{\mathrm{p}}$ phase will have an effect on the propagation path of the main crack and on the energy expended in its propagation. For example, in the UFG1 sample the transverse boundaries of the $\alpha_{\mathrm{p}}$ phase cause the deflection and even branching of the main crack, which requires significant energy expenditure to overcome the obstacle in the form 
of a boundary. On the contrary, in the UFG2 sample, significantly less energy is required for the formation of microcracks and pores in parallel to elongated interphase boundary before the tip of the main crack.

In the paper [17] the authors considered the micromechanisms controlling the fracture toughness of metals and alloys with different grain sizes. Also, they put forward an explanation of the differences in fracture toughness of UFG and NS metals, when the direction of crack propagation is parallel or perpendicular to the elongated grains in the microstructure. The authors believe that the initiation and coalescence of the pores is governed by plastic deformation and by grain boundary de-cohesion. This should be energetically easier when the majority of grain boundaries are aligned parallel to the pre-crack than perpendicular to it, leading to crack bifurcation. A similar failure mechanism was reported for different BCC and FCC metals [17, 28-30].

It is apparent from this investigation that the fracture toughness of UFG Ti alloys may be increased by increasing the extent of uniform elongation of the samples during tension. In earlier studies with commercial purity $\mathrm{Ti}$ this possibility was demonstrated without reducing the ultimate tensile strength by introducing low-temperature annealing and increasing the fraction of high-angle boundaries and the formation of segregation at the grain boundaries [31, 32]. This same approach can be applicable for two-phase Ti alloys but it now requires a more careful study directed towards determining a compromise between the strength, ductility and fracture toughness of these materials. This represents an important objective for future research.

\section{Summary and conclusions}

1. ECAP was combined with TMT to form a duplex UFG structure wherein $\sim 70 \%$ consisted of areas with equiaxed ultrafine $\alpha$-phase grains with an average size of $\sim 350 \mathrm{~nm}$ and the remaining volume was occupied by elongated poorly-deformed grains of the primary $\alpha$ phase with lengths up to $\sim 10 \mu \mathrm{m}$. 
2. The duplex UFG structure formation in the Ti-6Al-4V alloy leads to an increase in the yield stress and a concomitant decrease in the fracture toughness at the cryogenic temperature of $-196{ }^{\circ} \mathrm{C}$ by comparison with the coarse-grained alloy. The elongated grains of the primary $\alpha$-phase play an important role in the failure character of the UFG alloy especially regarding their orientation with respect to the testing direction. Thus, the lowest fracture toughness values $\left(\sim 28 \mathrm{MPa} \cdot \mathrm{m}^{-2}\right)$ were obtained for samples in which the elongated grains were parallel, as opposed to perpendicular, to the loading direction.

3. The results demonstrate that control of the fracture toughness, $K_{\mathrm{IC}}$, in the UFG Ti-6Al$4 \mathrm{~V}$ alloy is possible by measuring the uniform elongation, $\delta_{\mathrm{u}}$, and/or the stress difference $(U T S-Y S)$ which characterize the material ability for strain hardening.

\section{Acknowledgements}

This work was supported by the Ministry of Education and Science of the Russian Federation. Sections 2, 3.1, 3.2, 3,3 within the scope of the basic part of the State Assignment (grant No 11.1235.2017), sections 3.4 and 4.0 of the RFBR grant №16-58-1006116. One of the authors was supported by the European Research Council under ERC Grant Agreement No. 267464-SPDMETALS (TGL). 


\section{References}

[1] M. Peters, J. Hemptenmacher, J. Kumpfert, C. Leyens, Structure and Properties of Titanium and Titanium Alloys, in: C. Leyens, M. Peters (Eds.), Titanium and Titanium Alloys. Fundamentals and Applications, Weinheim, Germany: Wiley-VCH, 2003, pp. 1-37.

[2] R. Boyer, G. Welsch, E.W. Collings (Eds.) Materials Properties Handbook: Titanium Alloys, ASM International, USA, 1998, p.1048.

[3] M.A. Meyers, A. Mishra, D.J. Benson, Mechanical properties of nanocrystalline materials, Prog. Mater. Sci. 51 (2006) 427-556. https://doi.org/10.1016/j.pmatsci.2005.08.003

[4] Y. Estrin, A. Vinogradov, Extreme grain refinement by severe plastic deformation: A wealth of challenging science, Acta Mater. $61 \quad$ (2013) 782-817. https://doi.org/10.1016/j.actamat.2012.10.038

[5] T.G. Langdon, Twenty-five years of ultrafine-grained materials: Achieving exceptional properties through grain refinement, Acta Mater. 61 (2013) 7035-7059. https://doi.org/10.1016/j.actamat.2013.08.018

[6] R.Z. Valiev, Y. Estrin, Z. Horita, T.G. Langdon, M.J. Zehetbauer, Y.T. Zhu, Fundamentals of superior properties in bulk NanoSPD materials, Mater. Res. Lett. 4 (2015) 1-21. https://doi.org/10.1080/21663831.2015.1060543

[7] R.Z. Valiev, I.V. Alexandrov, Y.T. Zhu, T.C. Lowe, Paradox of strength and ductility in metals processed by severe plastic deformation, J. Mater. Res. 17 (2002) 5-8. https://doi.org/10.1557/JMR.2002.0002

[8] R.S. Mishra, V.V. Stolyarov, C. Echer, R.Z. Valiev, A.K. Mukherjee, Mechanical behavior and superplasticity of a severe plastic deformation processed nanocrystalline $\mathrm{Ti}-6 \mathrm{Al}-4 \mathrm{~V}$ alloy, Mater. Sci. Eng. A 298 (2001) 44-50. https://doi.org/10.1016/S0921-5093(00)01338-1

[9] S.V. Zherebtsov, G.A. Salishchev, R.M. Galeyev, O.R. Valiakhmetov, S.Yu. Mironov, S.L. Semiatin, Production of submicrocrystalline structure in large-scale Ti-6Al-4V billet by warm severe deformation processing, Scripta Mater. 51 (2004) 1147-1151. https://doi.org/10.1016/j.scriptamat.2004.08.018

[10] H.J. Rack, J. Qazi, L. Allard, R. Valiev, Thermal stability of severe plastically deformed VT-6 (Ti-6Al-4V), Mater. $\quad$ Sci. Forum, 584-586 (2008) 893-898. https://doi.org/10.4028/www.scientific.net/MSF.584-586.893

[11] I.P. Semenova, E.B. Yakushina, V.V. Nurgaleeva, R.Z. Valiev, Nanostructuring of Tialloys by SPD processing to achieve superior fatigue properties, Int. J. Mater. Res. 100 (2009) 1691-1696. https://doi.org/10.3139/146.110234 
[12] L.R. Saitova, H.W. Hoeppel, M. Goeken, I.P. Semenova, R.Z. Valiev, Cyclic deformation behavior and fatigue lives of ultrafine-grained Ti-6AL-4V ELI alloy for medical use, Int. J. Fatigue 31 (2009) 322-331. https://doi.org/10.1016/j.ijfatigue.2008.08.007

[13] I.P. Semenova, A.V. Polyakov, V.V. Polyakova, Y. Huang, R.Z. Valiev, T.G. Langdon, High-cycle fatigue behavior of an ultrafine-grained $\mathrm{Ti}-6 \mathrm{Al}-4 \mathrm{~V}$ alloy processed by ECAP and extrusion, Adv. Eng. Mater. 18 (2016) 2057- 2062. https://doi.org/10.1002/adem.201500630

[14] H. Shahmir, T.G. Langdon, An evaluation of the hexagonal close-packed to face-centered cubic phase transformation in a Ti-6Al-4V alloy during high-pressure torsion, Mater. Sci. Eng. A 704 (2017) 212-217. https://doi.org/10.1016/j.msea.2017.07.099

[15] A. Hohenwarter, R. Pippan, An overview on the fracture behavior of metals processed by high pressure torsion, Mater. Sci. Forum 667-669 (2011) 671-676. https://doi.org/10.4028/www.scientific.net/MSF.667-669.671

[16] A. Hohenwarter, R. Pippan, Fracture and fracture toughness of nanopolycrystalline metals produced by severe plastic deformation. Phil. Trans. R. Soc. A 373 (2015) 20140366. https://doi.org/10.1098/rsta.2014.0366

[17] R. Pippan, A. Hohenwarter, The importance of fracture toughness in ultrafine and nanocrystalline bulk materials, Mater. Res. Lett. 4 (2016) 127-136. https://doi.org/10.1080/21663831.2016.1166403

[18] E. Ma, Instabilities and ductility of nanocrystalline and ultrafine-grained metals, Scripta Mater. 49 (2003) 663-668. https://doi.org/10.1016/S1359-6462(03)00396-8

[19] R.K. Gupta, C. Mathew, P. Ramkumar, Strain hardening in aerospace alloys, Front. Aerosp. Eng. 4(1) (2015) 1-11. https://doi.org/10.12783/fae.2015.0401.01

[20] X. Huang, N. Hansen, N. Tsuji, Hardening by annealing and softening by deformation in nanostructured metals, Science 312 (2006) 249-251. https://doi.org/10.1126/science.1124268

[21] ASTM E399-90(1997), Standard Test Method for Plane-Strain Fracture Toughness of Metallic Materials, ASTM International, West Conshohocken, PA, 1997. https://doi.org/10.1520/E0399-90R97

[22] E.D. Tabachnikova, A.V. Podolskiy, V.Z. Bengus, S.N. Smirnov, K. Csach, J. Miskuf, L.R. Saitova, I.P. Semenova, R.Z. Valiev, Low temperature mechanical properties and failure peculiarities of the Ti-6Al-4V ELI ultra-fine grained alloy, Rev. Adv. Mater. Sci. 18 (2008) 604607. http://www.ipme.ru/e-journals/RAMS/no_71808/tabachnikova.pdf

[23] Y. Estrin, A. Vinogradov, Fatigue behavior of light alloys with ultrafine grain structure produced by severe plastic deformation: An overview, Intl J. Fatigue 32 (2010) 898-907. https://doi.org/10.1016/j.ijfatigue.2009.06.022 
[24] P. Kumar, M. Kawasaki, T.G. Langdon, Review: Overcoming the paradox of strength and ductility in ultrafine-grained materials at low temperatures, J. Mater. Sci. 51 (2016) 7-18. https://doi.org/10.1007/s10853-015-9143-5

[25] X. Peng, H. Guo, T. Wang, Z. Yao, Effects of $\beta$ treatments on microstructures and mechanical properties of TC4-DT titanium alloy, Mater. Sci. Eng. A 533 (2012) 55-63. https://doi.org/10.1016/j.msea.2011.11.033

[26] T. Dursun, C. Soutis, Recent developments in advanced aircraft aluminium alloys, Mater. Des. 56 (2014) 862-871. https://doi.org/10.1016/j.matdes.2013.12.002

[27] H. Shao, D. Shan, Y. Zhao, P. Geb, W. Zeng, Accordance between fracture toughness and strength difference in TC21 titanium alloy with equiaxed microstructure, Mater. Sci. Eng. A 664 (2016) 10-16. https://doi.org/10.1016/j.msea.2016.02.088

[28] A. Hohenwarter, C. Kammerhofer, R. Pippan, The ductile to brittle transition of ultrafinegrained Armco iron: an experimental study, J. Mater. Sci. 45 (2010) 4805-4812. https://doi.org/10.1007/s10853-010-4635-9

[29] A. Hohenwarter, R. Pippan, Anisotropic fracture behavior of ultrafine-grained iron, Mater. Sci, Eng. A 527 (2010) 2649-2556. https://doi.org/10.1016/j.msea.2009.12.033

[30] A. Hohenwarter, R. Pippan, Fracture of ECAP-deformed iron and the role of extrinsic toughening mechanisms, Acta Mater. $61 \quad$ (2013) 2973-2983. https://doi.org/10.1016/j.actamat.2013.01.057

[31] R.Z. Valiev, A.V. Sergueeva, A.K. Mukherjee, The effect of annealing on tensile deformation behavior of nanostructured SPD titanium, Scr. Mater. 49 (2003) 669-674. https://doi.org/10.1016/S1359-6462(03)00395-6

[32] I.P. Semenova, G.H. Salimgareeva, G. Da Costa, W. Lefebvre, R.Z. Valiev, Enhanced strength and ductility of ultra-fine grained Ti processed by severe plastic deformation, Adv. Eng. Mater. 12 (2010) 803-807. https://doi.org/10.1002/adem.201000059 
Table 1. Mechanical properties at room temperature and cryogenic temperature.

\begin{tabular}{|c|r|c|c|c|c|c|}
\hline \multirow{2}{*}{ States } & $T,{ }^{\circ} \mathrm{C}$ & $d_{\text {av. }}, \mu \mathrm{m}$ & $\begin{array}{r}U T S, \\
\mathrm{MPa}\end{array}$ & $\begin{array}{c}0.2 Y S, \\
\mathrm{MPa}\end{array}$ & Elong., \% & $\begin{array}{c}\text { Uniform } \\
\text { Elong., \% }\end{array}$ \\
\hline \multirow{2}{*}{$\mathrm{HT}$} & 25 & 15.00 & 950 & 850 & 12.0 & 2.8 \\
\cline { 2 - 7 } & -196 & & 1580 & 1480 & 11.0 & 2.5 \\
\hline \multirow{2}{*}{ UFG1 } & 25 & 0.35 & 1180 & 1070 & 9.0 & 1.1 \\
\cline { 2 - 7 } & -196 & & 1780 & 1720 & 7.3 & 1.3 \\
\hline \multirow{2}{*}{ UFG2 } & 25 & 0.50 & 1190 & 1120 & 10.8 & 1.0 \\
\cline { 2 - 7 } & -196 & & 1780 & 1750 & 6.8 & 0.7 \\
\hline
\end{tabular}

Table 2. Fracture toughness of Ti-6Al-4V alloy at $-196^{\circ} \mathrm{C}$.

\begin{tabular}{|l|c|c|c|c|}
\hline \multicolumn{1}{|c|}{ States } & $K_{\mathrm{IC}}, \mathrm{MPa} \cdot \mathrm{M}^{-2}$ & $t /\left(K_{\mathrm{IC}} / Y S_{2}\right)^{2}$ & $Y S$ & $\begin{array}{c}\text { Uniform } \\
\text { elong.\% }\end{array}$ \\
\hline HT & $48 \pm 2.9$ & 9.5 & 1480 & 2.5 \\
\hline UFG1 & $34 \pm 1.0$ & 26 & 1720 & 1.3 \\
\hline UFG2 & $28 \pm 1.0$ & 36 & 1750 & 0.7 \\
\hline
\end{tabular}

Table 3. Dependence of fracture toughness, $K_{\mathrm{IC}}$, on uniform elongation and difference (UTS-YS) for Ti alloys

\begin{tabular}{|c|c|c|}
\hline Parameters & Linear regression equation & $R^{2}$ \\
\hline Uniform elongation $\left(\delta_{\mathrm{u}}\right)$ & $Y=19.88+11.19 \mathrm{x}$ & 0.99 \\
\hline Difference $(U T S-Y S)$ at $T=-196^{\circ} \mathrm{C}$ for Ti-6Al-4V & $Y=17.24+0.30 \mathrm{x}$ & 0.99 \\
\hline Difference $(U T S-Y S)$ at $T=25^{\circ} \mathrm{C}$ for TC21 alloy $[27]$ & $Y=32.91+0.31 \mathrm{x}$ & 0.99 \\
\hline
\end{tabular}


Fig. 1. Schemes of samples cutting from billets after ECAP (a) and ECAP+TMT (b) for fracture toughness tests.

Fig. 2. Microstructure of the Ti-6Al-4V alloy after HT (quenching from $T=960{ }^{\circ} \mathrm{C}, 1 \mathrm{~h} .+$ annealing at $T=675{ }^{\circ} \mathrm{C}$, 4h.) relative to testing direction: a) SEM-image of the overall view; b) $\alpha+\beta$ regions.

Fig. 3. The UFG1 microstructure of Ti-6Al-4V alloy after ECAP: a) overall view; b) $\alpha+\beta$ regions; c) primary $\alpha$-phase grains. The arrow depicts the testing direction.

Fig. 4. The UFG2 microstructure of Ti-6Al-4V alloy after ECAP and TMT: a) overall view; b) $\alpha+\beta$ regions. The arrow depicts the testing direction.

Fig.5. Typical stress-strain curves at $25{ }^{\circ} \mathrm{C}$ and $-196{ }^{\circ} \mathrm{C}$ of Ti-6Al-4V alloy in HT, UFG1 and UFG2 states.

Fig. 6. Dependence of $K_{\mathrm{IC}}$ on the uniform elongation, $\delta_{\mathrm{u}}$, at $-196{ }^{\circ} \mathrm{C}$ of Ti-6Al-4V with $\mathrm{CG}$, UFG1 and UFG2 microstructures.

Fig. 7. Views of fracture surfaces of Ti-6Al-4V alloy: (a, b) CG state; (c, d) UFG1 state: (e, f) UFG2 state. The arrows depict the start of brittle separation in all samples from the grown fatigue crack (the pre-crack).

Fig. 8. SEM images of fracture surfaces of samples with (a) UFG1 and (b) UFG2 microstructures after testing.

Fig. 9. Dependence of $K_{\mathrm{IC}}$ on the difference of $U T S$ and $Y S$ for the Ti-6Al-4V alloy at $25^{\circ} \mathrm{C}$ (298K) [2] and at $-196^{\circ} \mathrm{C}(77 \mathrm{~K})$ [current work]. 
a

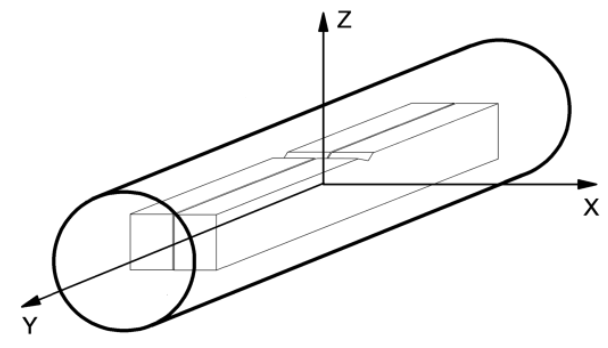

b

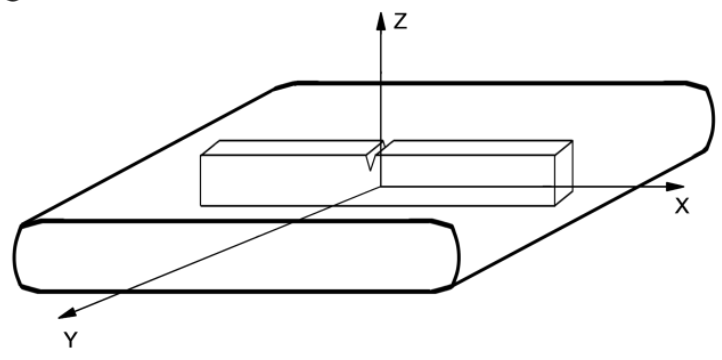

Fig. 1
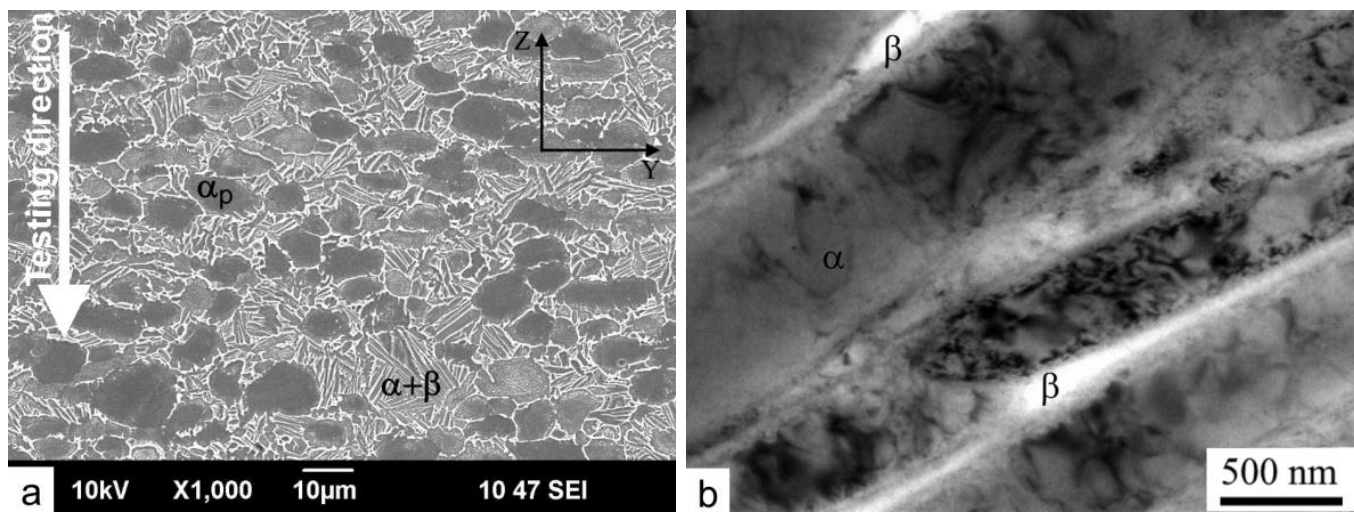

Fig. 2
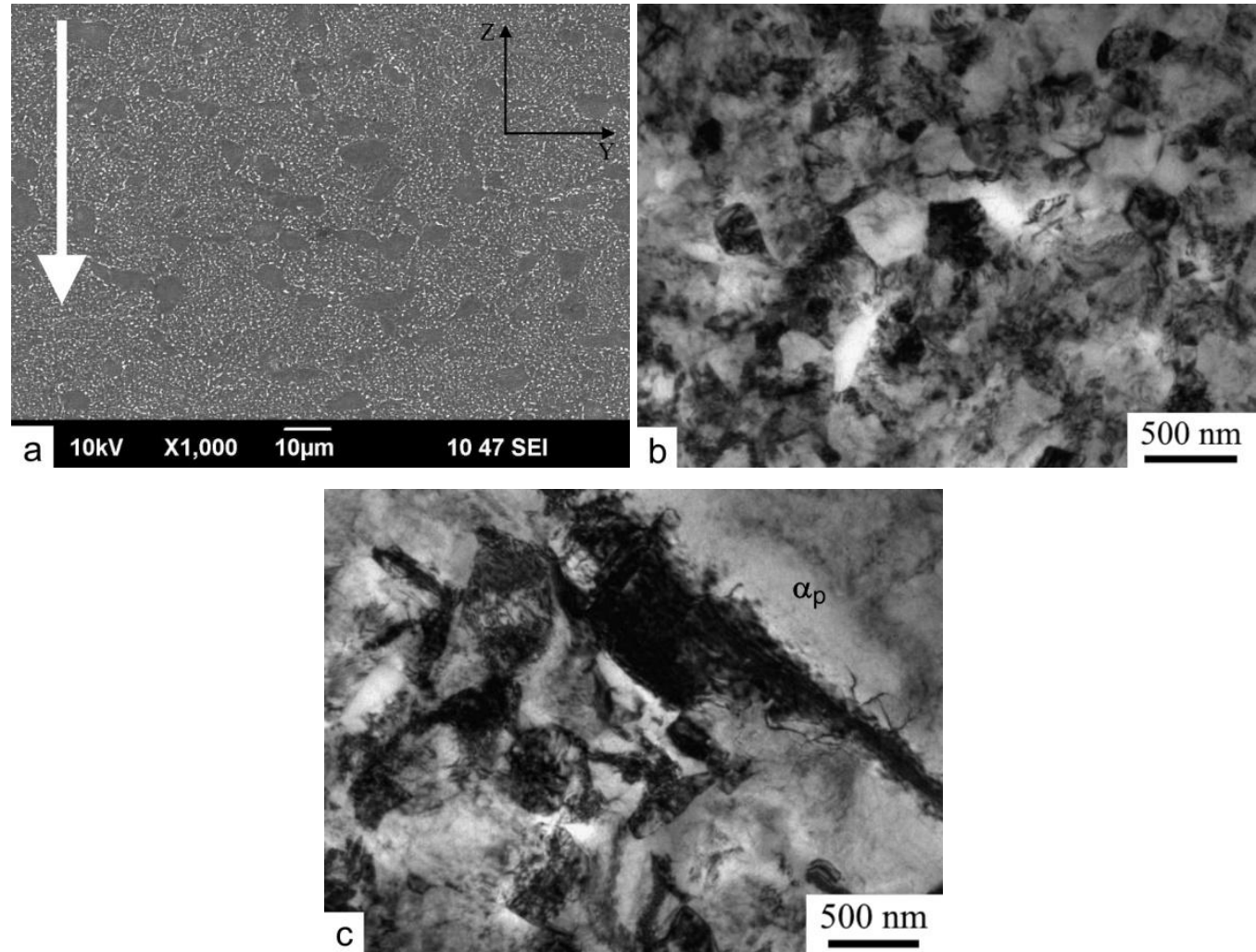

Fig. 3 

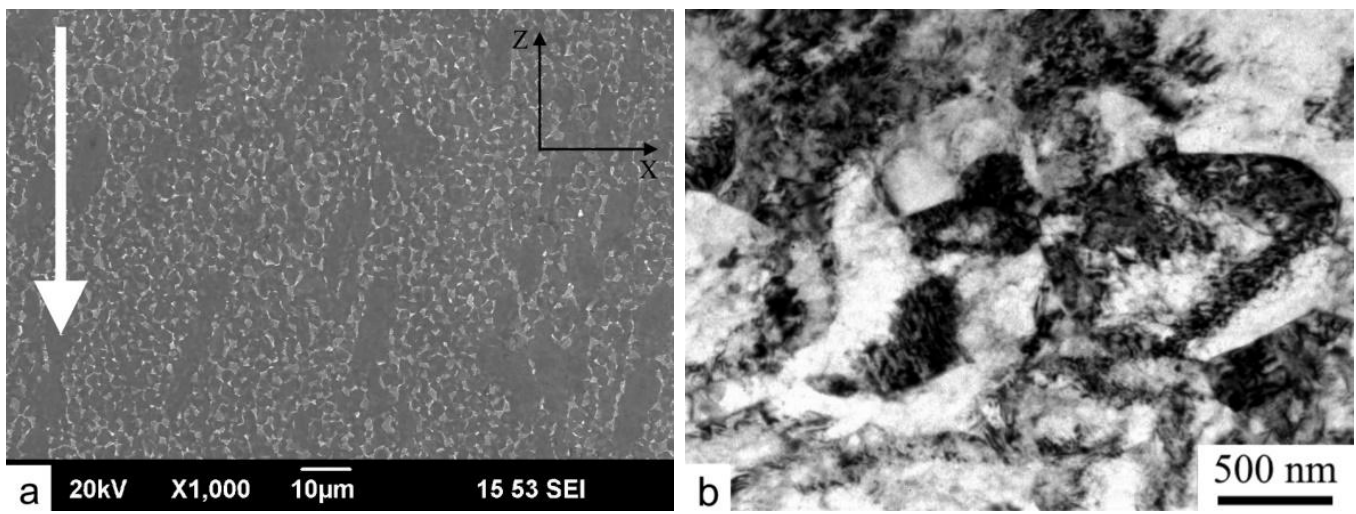

Fig. 4

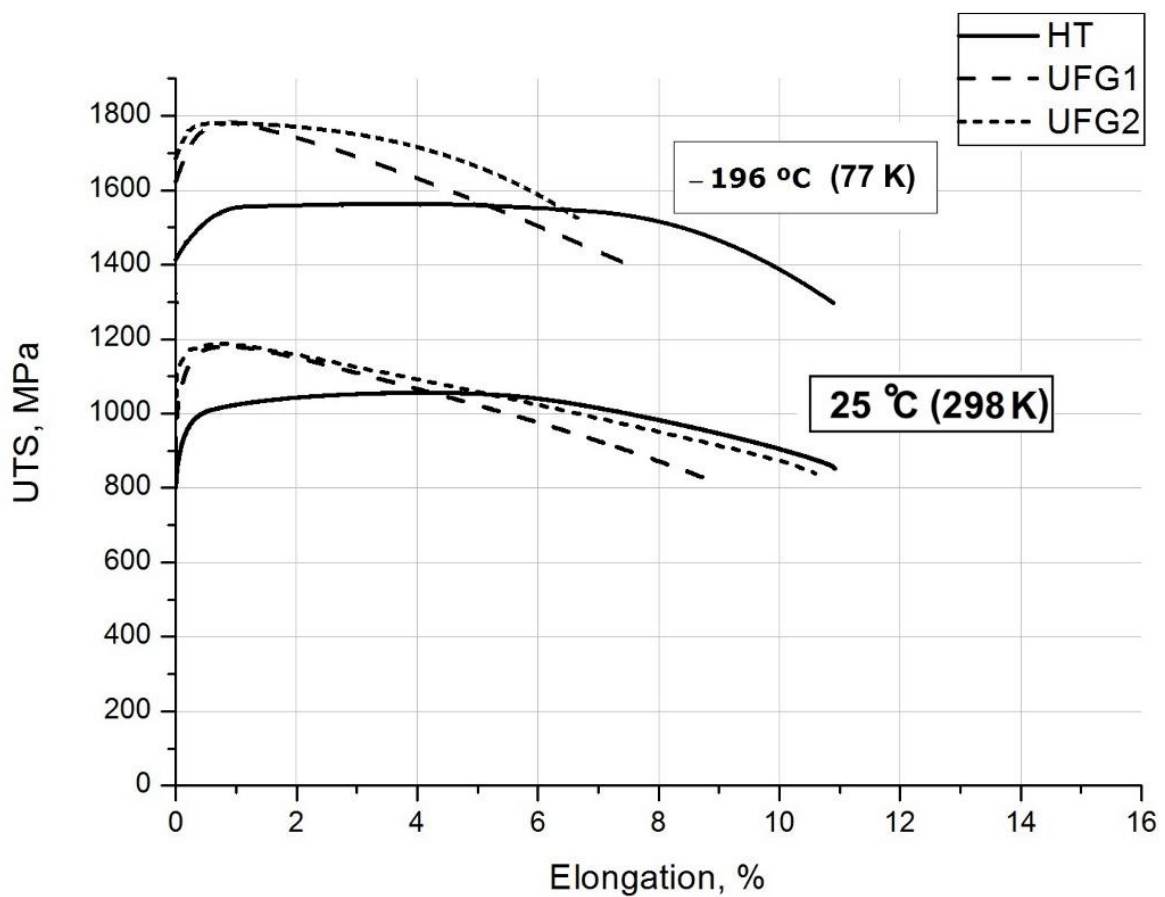

Fig.5 


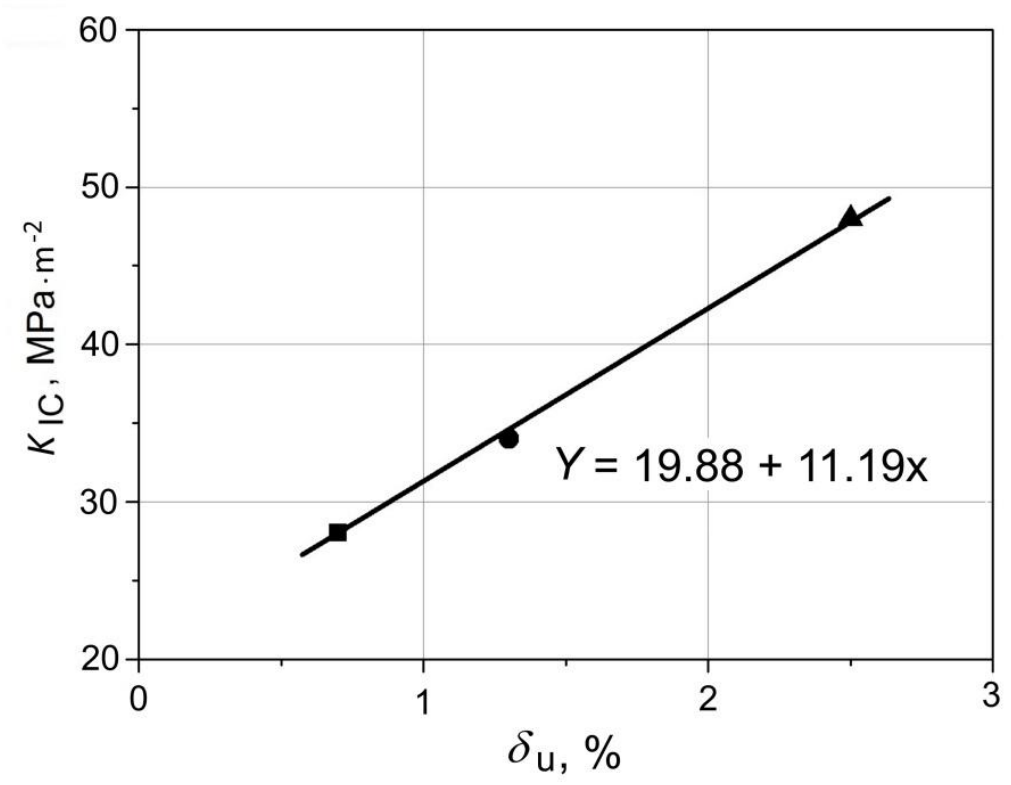

Fig. 6

a
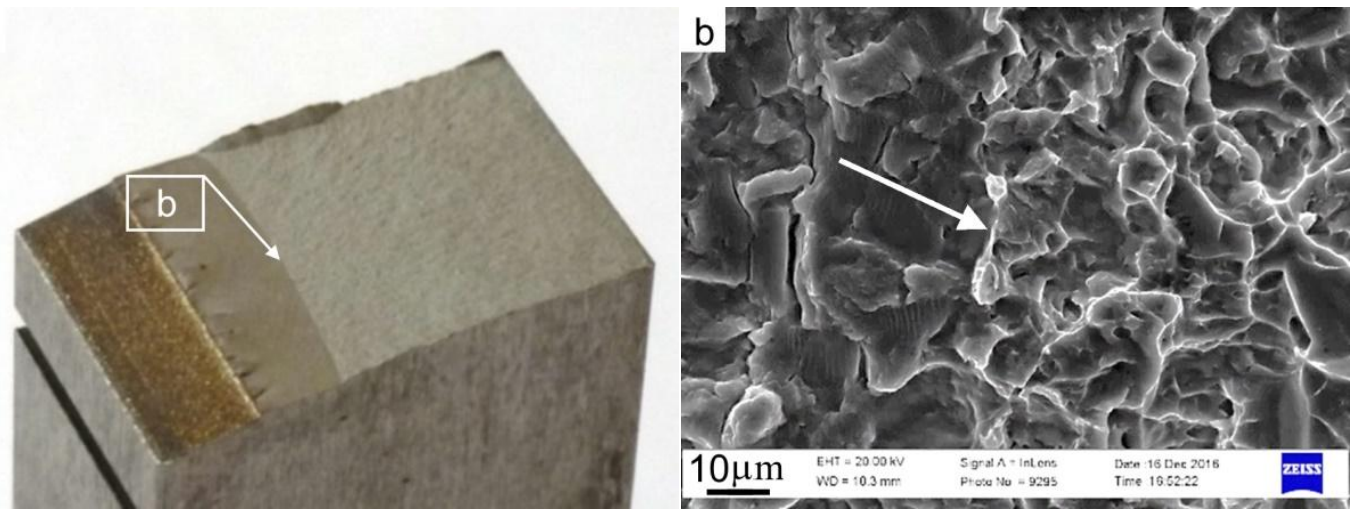

C
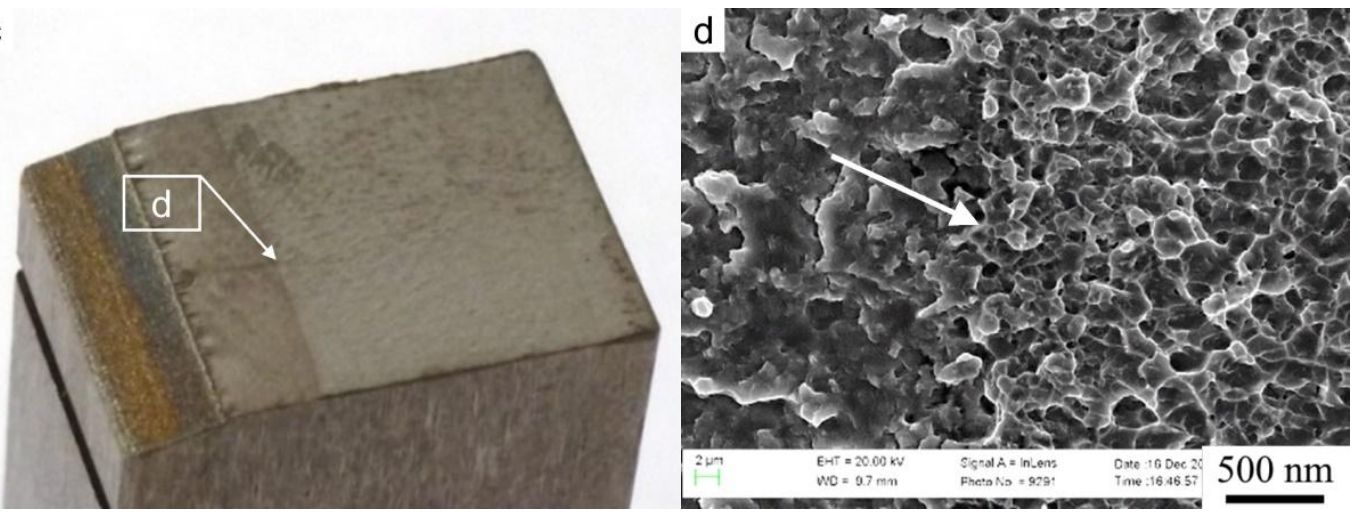